\title{
Effects of Methodological Difference on Fine Root Production, Mortality and Decomposition Estimates Differ Between Functional Groups in A Planted Loblolly Pine Forest
}

Xuefeng Li ( $\nabla$ lxf.victor@gmail.com )

North Carolina State University https://orcid.org/0000-0002-7783-9942

Quanlai Zhou

Xingbo Zheng

Michael Gavazzi

Yanlong Shan

Steve McNulty

John S. King

\section{Research Article}

Keywords: Fine root, production, mortality, decomposition, method, loblolly pine

Posted Date: February 24th, 2022

DOI: https://doi.org/10.21203/rs.3.rs-1367018/v1

License: (c) (i) This work is licensed under a Creative Commons Attribution 4.0 International License.

Read Full License 
1 Effects of methodological difference on fine root production, mortality and decomposition

2 estimates differ between functional groups in a planted loblolly pine forest

3 Xuefeng $\mathrm{Li}^{1,4 *}$, Xingbo Zheng ${ }^{1}$, Quanlai Zhou ${ }^{1}$, Michael Gavazzi ${ }^{2}$, Yanlong Shan ${ }^{3}$, Steven

4 McNulty $^{2}$, John S. King ${ }^{4}$,

$5{ }^{1}$ Institute of Applied Ecology, Chinese Academy of Sciences, Shenyang City, 110016 China

$6 \quad{ }^{2}$ USDA Forest Service, Eastern Forest Environmental Threat Assessment Center, Raleigh, NC,

7 United States

$8 \quad{ }^{3}$ Department of Forestry, Beihua University, Jilin City, 132013 China

$9{ }^{4}$ Department of Forestry and Environmental Resources, North Carolina State University,

10 Raleigh, NC, 27695, United States

$11 *$ Corresponding author: lxf.victor@ gmail.com; Tel (919) 376-7856

12 Abstract

13 Background and aims Fine roots can be functionally classified into an absorptive fine root pool

14 (AFR) and a transport fine root pool (TFR) and their production, mortality and decomposition

15 play a critical role in forest soil carbon (C) cycling. Different methods give significantly different

16 estimates. However, how methodological difference affects AFT and TFR production, mortality,

17 and decomposition estimates remains unclear, impeding us to accurately construct fine root $\mathrm{C}$

18 budgets.

19 Methods We used dynamic-flow model, a model based on measurements of litterbags and soil

20 cores, and balanced-hybrid model, a model based on measurements of minirhizotrons and soil 
21 cores, to quantify AFT and TFR production, mortality, and decomposition in a planted loblolly

22 pine forest.

23 Results Temporal changes in AFR and TFR production, mortality and decomposition estimates

24 were generally the same between the two models. Annual production, mortality, and

25 decomposition were comparable between AFRs and TFRs when measured using the dynamic-

26 flow model but significantly higher for AFRs than for TFRs when measured using the balanced-

27 hybrid model. Annual production, mortality and decomposition estimates using the balanced-

28 hybrid model were $75 \%, 71 \%$ and $69 \%$ higher than those using the dynamic-flow model,

29 respectively, for AFRs, but $12 \%, 6 \%$ and $5 \%$ higher than those using the dynamic-flow model,

30 respectively, for TFRs. Model test showed that the balanced-hybrid model had greater accuracy

31 than the dynamic-flow model in estimating AFR and TFR production, mortality and

32 decomposition. Lower AFR estimates using the dynamic-flow model than using the balanced-

33 hybrid model appeared to result from the underestimated AFR mass loss rate induced by the

34 litterbag method.

35 Conclusions The balanced-hybrid model is more reliable than the dynamics-flow model.

36 Methodological difference has greater effects on AFR estimates than TFR estimates. Effects of

37 methodological difference must be taken into consideration when quantifying fine root

38 production, mortality and decomposition by functional groups.

39 Key words Fine root $\cdot$ production $\cdot \operatorname{mortality} \cdot$ decomposition $\cdot \operatorname{method} \cdot$ loblolly pine

40 Introduction

41 Fine roots are the most physiologically active component of the below-ground plant system

42 (McCormack et al. 2015). Studies conducted at the ecosystem scale showed that fine root 
43 production consumed up to 63\% of forests' net primary production (Vogt 1991; Litton et al.

44 2007). Fine root mortality accounted for nearly half of organic carbon (C) input into the soil

45 (Ding et al. 2019), while fine root decomposition (i.e. amount of dead fine roots decomposed)

46 represented around $10 \%$ of soil heterotrophic $\mathrm{C}$ emission in planted loblolly pine forests (Li et al.

47 2020a). Thus, accurate measurements of fine root production, mortality and decomposition in

48 forests are critical for quantifying forest $\mathrm{C}$ allocation and cycling and parameterizing climate

49 change models (Woodward and Osborne 2000; Ghimire et al. 2016).

50 Ingrowth core and soil core methods, which are low cost and ready-to-use, had been

51 extensively applied to assess fine root production and mortality (Vogt et al. 1998; Brunner et al.

52 2013; Addo-Danso et al. 2016). However, these methods miss fine root dying and decomposing

53 processes during sampling intervals, resulting in great uncertainties in the estimates (Osawa and

54 Aizawa 2012). To overcome this weakness, several improved ingrowth core/soil core models

55 have been developed in which fine root biomass and necromass dynamics and mass loss rate

56 were integrated into mass balance equations (Santantonio and Grace 1987; Osawa and Aizawa

57 2012; Li et al. 2013). Dynamic-flow model is a new improved soil core model (Li and Lange

58 2015) and the model structure is the same as that in Osawa and Aizawa (2012) except that fine

59 root decomposition rate is assumed to decrease over time. In theory, the dynamic-flow model

60 has greater estimation accuracy than other modified soil coring methods. This is because fine

61 root decomposition rate has been found to decline with time rather than remain constant due to

62 the facts that the labile and recalcitrant components in fine roots have different mass loss rates,

63 with the former being depleted much faster than the latter (Fan and Guo 2010; Lin et al. 2011).

64 Minirhizotron technique is a visual method of studying roots in which clear tubes are inserted

65 into the ground and miniature cameras are used to capture the photographic images of roots 
growing on the tube surface (Hendrick and Pregitzer 1993). It allows to monitor the growth and

67 death of individual fine roots continuously while overcoming the cofounding of spatiotemporal variation (McCormack et al. 2014, 2015). Combining minirhizotrons and soil cores enables to quantify fine root production and mortality but fails to assess fine root decomposition, an important component in soil C fluxes (Hendricks et al. 2006; Addo-Danso et al. 2016). The

71 balanced-hybrid model is an improved minirhizotron-based model in which measurements of

72 soil cores and minirhizotrons are integrated into mass balance equations (Li et al. 2020a). It can

73 be used to quantify not only fine root production and mortality but also fine root decomposition.

74 Fine roots have been traditionally defined as distal roots with diameters $<2 \mathrm{~mm}$. Recent studies 75 have shown that the hierarchical root system is morphologically, chemically and functionally 76 heterogeneous and can be partitioned into two pools: absorptive fine roots (AFRs) and transport 77 fine roots (TFRs) (McCormack et al. 2015; Kou et al. 2018). AFRs represent the most distal 78 roots and involve primarily in the absorption of soil resources, while TFRs occur higher in the 79 branching hierarchy and function mainly as resource transportation and storage. AFRs have 80 relatively higher $\mathrm{N}$ concentration and shorter lifespan when compared with TRFs (McCormack 81 et al. 2015). Studying fine roots as two functional pools instead of a single diameter-based pool 82 enables a more accurate characterization of fine root processes (Sun et al. 2012). It has been 83 recommended that multiple methods should be used to yield more reliable fine root estimates 84 (Hendricks et al. 2006; Addo-Danso et al. 2016). However, AFR and TFR production, mortality 85 and decomposition have not been jointly quantified using dynamic-flow and balanced-hybrid 86 models, leading to significant uncertainties in forest $\mathrm{C}$ budgets. Planted loblolly pine (Pinus

87 taeda L.) forests cover 11 million hectares in the US, accounting for $50 \%$ of the standing pine 88 volume in the southern USA (Wear and Greis 2012). It has been estimated that over 1 billion 
seedlings are planted annually (Wear and Greis 2012). An improved understanding of AFR and

90 TFR dynamics in planted loblolly pine forests is critical for developing silvicultural and rotation

91 strategies to increase $\mathrm{C}$ sequestration capacity, in particular the large soil pools.

92 In this study, we used the soil core method, litterbags, and minirhizotrons to assess biomass

93 and necromass dynamics, mass loss pattern and growth and death rates of AFRs and TFRs in a

94 planted loblolly pine forest. The objectives were to 1) use both the dynamic-flow model and the

95 balanced-hybrid model to quantify AFR and TFR production, mortality, and decomposition in

96 this forest, 2) assess to what extent methodological difference affects AFR and TFR estimates

97 and 3) determine which method is more reliable.

99 Materials and methods

100 Study site

101 The study was conducted in a commercially managed loblolly pine (P. taeda L.) forest (35 $48^{\prime} \mathrm{N}$ $10276^{\circ} 40^{\prime} \mathrm{W}$ ) located in the lower coastal plain of Washington County, North Carolina, USA. Mean 103 annual precipitation and temperature for the period $2011-2017$ were $1320 \mathrm{~mm}$ and $12.2{ }^{\circ} \mathrm{C}$, 104 respectively. The topography of the area is flat ( $<5 \mathrm{~m}$ above sea level) and on a Belhaven series 105 histosol soil (loamy mixed dysic thermic terric Haplosaprists). The study area was harvested of 106 trees and ditched/drained in the late 19th to the early 20th century and farmed for about a decade 107 before being converted to a commercial pine plantation forest. The usual rotation period is 108 around 30 years. The forest was fertilized with nitrogen and phosphorus at the time of planting 109 and mid-rotation. The soil $\mathrm{C}$ and nitrogen concentrations at $20 \mathrm{~cm}$ depth were $26 \%$ and $1.0 \%$, 110 respectively. The mean canopy height, diameter at the breast height, and stand age during the 
111 study period were approximately $24 \mathrm{~m}, 33 \mathrm{~cm}$, and 23 years, respectively. For a full site

112 description, refer to Noormets et al. (2010). Three plots, 100m to 800m apart, were established at

113 random in the planted forest in 2013. Each plot was about $6 \mathrm{~m} \times 9 \mathrm{~m}$ in size. Only loblolly pine

114 fine roots were studied.

116 Fine root biomass and necromass measurements

117 Fine root biomass and necromass were measured using the soil coring method. The number of

118 soil cores required at both plot and stand-level was calculated using the methods in Bartlett et al.

119 (2001) and Dornbush et al. (2002). In each plot, 8 cylindrical soil cores $(3.0 \mathrm{~cm}$ diameter, $30 \mathrm{~cm}$

120 depth) were randomly collected on 6 sampling occasions from April 2016 to April 2017, forming

1215 soil sampling intervals (Li et al. 2020a) (Table 1). Previous study showed that over $90 \%$ of fine

122 roots were distributed in $0-30 \mathrm{~cm}$ soil layer in this forest (Noormets et al. 2010; Li et al. 2020a).

123 Collected soil cores were rinsed with clean tap water through a $0.5 \mathrm{~mm}$ mesh sieve to isolate

124 roots. We only studied loblolly pine fine roots as they accounted for over $95 \%$ of total fine root

125 mass in $0-30 \mathrm{~cm}$ soil layer. Loblolly pine fine roots with light color and intact stele and

126 periderm were regarded as live roots, while those with dark color and damaged stele and

127 periderm were dead ones. In this study, AFRs represented the first and second-order roots, while

128 TFRs were third-order roots and higher with diameter < 2mm (Pregitzer et al. 2002; McCormack

129 et al. 2015). Live and dead AFRs and TFRs were separated according to the procedures

130 described in Li et al. (2020b). All fine roots were dried at $50{ }^{\circ} \mathrm{C}$ to a constant weight and

131 weighed. The measurements of biomass and necromass in the soil cores were scaled to $\mathrm{g} \mathrm{m}^{-2}$ over

132 a 0-0.30 m soil layer. 
135 AFR and TFR mass loss rates were assessed using litterbags. To provide input parameters for

136 dynamic-flow model, we used four types of fine roots including live and dead AFRs and TFRs as

137 the decomposing substrates in in situ decomposition experiments. The decomposing substrates 138 were from the fine roots in soil cores collected in July 2016 as they had already been sorted out 139 by functional groups and vitality. Each litterbag $(20 \mathrm{~cm} \times 3.5 \mathrm{~cm}, 0.05 \mathrm{~mm}$ mesh) was evenly 140 filled with about $0.15 \mathrm{~g}$ fine root materials and inserted vertically into a $0-20 \mathrm{~cm}$ of soil. This 141 experimental design intended to have fine root materials distributed evenly in different soil 142 layers. The decomposition experiment began on 8 August 2016. The litterbags were collected 143 after 65, 105 and 310 days of incubation. On each sampling occasion, three litterbags of each of 144 the four root types were retrieved from each plot. Roots from the litterbags were rinsed with 145 clear tap water, carefully sorted, dried at $50{ }^{\circ} \mathrm{C}$ to a constant weight and then weighed.

147 Dynamic-flow model

148 AFR and TFR production, mortality and decomposition were determined using the dynamic-flow 149 model (Li and Lange 2015; Li et al. 2020b). Interval $i$ was any given soil coring interval $(1 \leq i)$ 150 (year). $\mathrm{G}_{\mathrm{I}-\mathrm{i}}$ and $\mathrm{G}_{\mathrm{II}-\mathrm{i}}$ were the fine roots that died before the start of interval $i$ and in interval $i$, 151 respectively. The mass loss patterns of $\mathrm{G}_{\mathrm{I}-\mathrm{i}}$ and $\mathrm{G}_{\mathrm{II}-\mathrm{i}}$ were simulated by the litterbag method with 152 dead and live roots used as decomposing substrates, respectively.

153 Fine root mass loss pattern was simulated using an exponential equation with only two 154 parameters: 


$$
y(t)=y_{0} e^{(-\lambda / k)\left(1-e^{-k t}\right)}
$$

where $y_{(\mathrm{t})}$ and $y_{0}$ are root mass at time $t$ (year) and the start, respectively. The two parameters

$157 \lambda\left(\right.$ year $\left.^{-1}\right)$ and $k\left(\right.$ year $\left.^{-1}\right)$ were calculated based on the fine root mass remaining in litterbags

158 collected on all sampling occasions using nonlinear regression. $\mathrm{e}^{-k t}$ is fine root decomposition

159 rate which is time-dependent. It is the highest at the beginning and decreases over time.

The fine root mortality rate in interval $i\left(\mu_{\mathrm{i}}\right)$ was assumed to be constant. The total production

$161\left(g_{\mathrm{i}}\right)$, mortality $\left(m_{\mathrm{i}}\right)$ and decomposition $\left(d_{\mathrm{i}}\right)$ in interval $i$ were calculated by the following

162 equations,

$$
\begin{array}{r}
g_{\mathrm{i}}=B_{\mathrm{i}}-B_{\mathrm{i}}(0)+m_{\mathrm{i}} \\
d_{\mathrm{i}}=m_{\mathrm{i}}-\left(N_{\mathrm{i}}-N_{\mathrm{i}}(0)\right) \\
N_{\mathrm{I}-\mathrm{i}}=N_{\mathrm{i}}(0) \mathrm{e}^{\left(-\lambda_{\mathrm{I}-\mathrm{i}} / k_{\mathrm{I}-\mathrm{i}}\right)\left(1-e^{-k_{\mathrm{I}-\mathrm{i}} T}\right)} \\
N_{\mathrm{II}-\mathrm{i}}=N_{\mathrm{i}}-N_{\mathrm{I}-\mathrm{i}} \\
m_{\mathrm{i}}=\mu_{\mathrm{i}} \mathrm{T}
\end{array}
$$

where $B_{\mathrm{i}}(0)$ and $B_{\mathrm{i}}$ represented the fine root biomass in soil cores sampled at the start and the end of interval $i$, respectively, $N_{\mathrm{i}}(0)$ and $N_{\mathrm{i}}$ represented the fine root necromass at the start and the end of interval $i$, and $N_{\mathrm{II}-\mathrm{i}}$ and $N_{\mathrm{I}-\mathrm{i}}$ were the mass remaining of $\mathrm{G}_{\mathrm{II}-\mathrm{i}}$ and $\mathrm{G}_{\mathrm{I}-\mathrm{i}}$ at end of interval $i$, respectively. T was time length of interval $i$.

$$
\mu_{\mathrm{i}}=k_{\mathrm{II}-\mathrm{i}} N_{\mathrm{II}-\mathrm{i}} \frac{e^{-\left(\lambda_{\mathrm{II}-\mathrm{i}} / k_{\mathrm{II}-\mathrm{i}}\right) e^{-k_{\mathrm{II}-\mathrm{i}} T}}}{E_{1}\left(\left(\lambda_{\mathrm{II}-\mathrm{i}} / k_{\mathrm{II}-\mathrm{i}}\right) e^{-k_{\mathrm{II}-\mathrm{i}} T}\right)-E_{1}\left(\lambda_{\mathrm{II}-\mathrm{i}} / k_{\mathrm{II}-\mathrm{i}}\right)}
$$

$$
E_{1}(z)=\int_{z}^{\infty} \frac{e^{-x}}{x} d x
$$


was an exponential integral function (Abramowitz and Stegun, 1964, ch. 6).

$171 B_{\mathrm{i}}(0), B_{\mathrm{i}}, N_{\mathrm{i}}, N_{\mathrm{i}}(0), N_{\mathrm{II}-\mathrm{i}}$, and $N_{\mathrm{I}-\mathrm{i}}$ had the unit $\mathrm{g} \cdot \mathrm{m}^{-2} \cdot g_{\mathrm{i}}, m_{\mathrm{i}}$ and $d_{\mathrm{i}}$ have the unit $\mathrm{g} \cdot \mathrm{m}^{-2} \mathrm{year}^{-1} \cdot \lambda_{\mathrm{I}-\mathrm{i}}$,

$172 k_{\mathrm{I}-\mathrm{i}}, \lambda_{\mathrm{II}-\mathrm{i}}$, and $k_{\mathrm{II}-\mathrm{i}}$ were decomposition parameters for $\mathrm{G}_{\mathrm{I}-\mathrm{i}}$ and $\mathrm{G}_{\mathrm{II}-\mathrm{i}}$, respectively, which can be

173 calculated using Eq.1. $B \mathrm{i}(0), B \mathrm{i}, N_{\mathrm{i}}$ and $N_{\mathrm{i}}(0)$ were measured using the soil cores, $N_{\text {II-i }}$ was

174 calculated by Eq. (4) and $m_{\mathrm{i}}=\mu_{\mathrm{i}} T$. Thus, $g_{\mathrm{i}}$ and $d_{\mathrm{i}}$ were calculated by Eqs. 2 and 3, respectively.

175

Minirhizotron measurements

177 A total of 18 acrylic tubes $\left(80 \mathrm{~cm}\right.$ long, $6 \mathrm{~cm}$ outer diameter) were installed in 2013 at a $45^{\circ}$ 178 angle to a vertical soil depth of $50 \mathrm{~cm}$ in the three plots (5 to 8 tubes per plot). Root scanning 179 began one year after tube installation to allow the soil around the tubes to stabilize. Only root 180 images taken between late April 2016 to late April 2017 were used as these images co-occurred 181 with soil coring (Li et al. 2020a) (Table 1). There were 17 image-capturing occasions during the 182 study period. Images were collected using a Bartz digital camera with the image capture software 183 BTC I-CAP (Bartz Technology Corp., Carpinteria, CA, USA). Fine root length and diameter 184 were quantified by analyzing the images with WinRHIZO software (Regents Instruments Inc., 185 Quebec, Canada). AFR and TFR length production, mortality and standing length density (mean 186 root length per unit root image area) were calculated based on the image analysis. Note that 187 AFRs and TFRs included both mycorrhizal and non-mycorrhizal fine roots. An AFR or TFR was 188 counted as dead if its diameter shriveled to half the original diameter, it showed signs of 189 deterioration including fragmenting and ectomycorrhizal fungal mantle detachment, or it was 190 consumed by soil animals; otherwise, roots were considered as living (McCormack et al. 2014; 191 Kou et al. 2018). 
194 Fine root length production $\left(\mathrm{LP}_{\mathrm{i}}, \mathrm{m} \mathrm{m}^{-2}\right.$ image $)$ and mortality $\left(\mathrm{LM}_{\mathrm{i}}, \mathrm{m} \mathrm{m}^{-2}\right.$ image $)$ in a given soil 195 coring interval $i$ were estimated from minirhizotron image analysis. LP $_{\mathrm{i}}$ and $\mathrm{LM}_{\mathrm{i}}$ were calculated 196 as the length of fine roots that were produced and died in interval $i$, respectively (Kou et al. 197 2018).

198 Fine root turnover $\left(\mathrm{TR}_{\mathrm{i}}\right)$ and death rates $\left(\mathrm{DR}_{\mathrm{i}}\right)$ in the interval were calculated as

$199 \quad \mathrm{TR}_{\mathrm{i}}=\mathrm{LP}_{\mathrm{i}} / \mathrm{SL}_{\mathrm{i}}$

$200 \quad \mathrm{DR}_{\mathrm{i}}=\mathrm{LM}_{\mathrm{i}} / \mathrm{SL}_{\mathrm{i}}$

201 where $\mathrm{SL}_{\mathrm{i}}$ is the mean standing live fine root length of minirhizotron images captured at the 202 start of interval $i\left(\mathrm{~m} \mathrm{~m}^{-2}\right.$ image).

$203 g_{\mathrm{i}}$ and $m_{\mathrm{i}}$ are assessed by combining measurements of minirhizotrons and soil cores 204 (Hendricks et al. 2006; Li et al. 2020a).

205

$$
g_{\mathrm{i}}=\mathrm{B}_{\mathrm{i}}(0) \times \mathrm{TR}_{\mathrm{i}} \quad(10)
$$

206

$$
m_{\mathrm{i}}=\mathrm{B}_{\mathrm{i}}(0) \times \mathrm{DR}_{\mathrm{i}}
$$

$207 \quad \mathrm{~B}_{\mathrm{i}}(0)$ is fine root biomass at the start of interval $i$.

208 Resorting to Eq. 3, $d_{\text {i }}$ can be calculated (Li et al. 2020a). 
211 The efficacy of the models for estimating the production, mortality, and decomposition was

212 tested by comparing the predicted with the measured AFR and TFR biomass in July. The reason

213 was that temperature and precipitation in April to July were comparable to those in July to

214 September. In dynamic-flow model testing, the interval April to July and the interval July to

215 September were combined into one and fine root production and mortality rates in the new

216 interval were assumed to be constant. AFR and TFR biomass and necromass in April and

217 September and AFR and TFR mass loss patterns were employed to calculate AFR and TFR

218 production, mortality and decomposition in April to September. The balance-hybrid model

219 testing was the same as that in Li et al. (2020a). The predicted AFR and TFR biomass in July

220 were calculated according to the procedures described in Hendrick and Pregitzer (1993),

221 Hendricks et al. (2006) and Li e al. (2020a). Smaller differences between predicted and measured

222 biomass values mean greater estimation accuracy.

224 Statistical analysis

225 The plots were considered as replicates $(n=3)$, and data collected (sub-replicates) within the 226 same plot were averaged before performing statistical analysis. One-way ANOVA was used to 227 assess the difference in means of measured fine root mass loss rates. Within each model, paired-t 228 test was performed to test the differences in the production, mortality and decomposition 229 between AFRs and TFRs. The data were log-transformed to normalize variances before analysis 230 when necessary. All data were analyzed using the SPSS statistical software (version 17.0; IBM 231 Corporation, Somers, NY 10589, USA).

\section{Results}


234 AFR and TFR biomass showed the same temporal pattern, with the highest values in July and the

235 lowest values in January, while AFR and TFR necromass did not show evident peak and trough

236 values during the whole study period (Fig. 1). AFRs had significantly lower mean biomass than

237 TFRs $\left(67.8 \pm 5.3\right.$ vs. $88.7 \pm 2.9 \mathrm{~g} \mathrm{~m}^{-2}$; mean $\left.\pm \mathrm{SE}\right)(P<0.05)$. The mean necromass of AFRs was

238 lower than that of TFRs $\left(41.2 \pm 2.8\right.$ vs. $50.4 \pm 5.2 \mathrm{~g} \mathrm{~m}^{-2}$; mean $\left.\pm \mathrm{SE}\right)$, but the difference was not

239 significant $(P>0.05)$.

241 Mass loss rate

242 Live AFR substrates had significantly higher percent mass remaining than live TFR substrates at

243 the end of the experiment, but dead AFR and TFR substrates had comparable percent mass

244 remaining during the whole study period (Fig. 2). All live root substrates decomposed

245 significantly faster than dead root substrates (Fig. 2).

247 Temporal changes in fine root estimates

248 Temporal changes in fine root production, mortality and decomposition rates were generally the

249 same between the two models, with greater production in February to July and greater mortality

250 and decomposition occurring in October to November (Fig. 3). Production, mortality, and

251 decomposition estimates using dynamic-flow model were comparable between AFRs and TFRs

252 at all intervals. In contrast, production, mortality, and decomposition estimates using the

253 balanced-hybrid model were significantly higher for AFRs than for TFRs in most intervals (Fig. 
254 3). AFR production, mortality and decomposition estimates using the dynamic-flow model were

255 lower than those using the balanced-hybrid model in most intervals, while TFR production,

256 mortality and decomposition estimates using the two models were between comparable in most

257 intervals (Fig. 3).

259 Annual fine root estimates

260 Annual production, mortality, and decomposition were not significantly different between AFRs

261 and TFRs when estimated using the dynamic-flow model, but significantly higher for AFRs than

262 for TFRs when estimated using the balanced-hybrid model (Fig. 4). Annual AFR production,

263 mortality, and decomposition estimates using the balanced-hybrid model were $75 \%, 71 \%$, and

$26469 \%$ higher than those using the dynamic-flow model, respectively (Fig. 4). By contrast, annual

265 TFR production, mortality, and decomposition estimates using the balanced-hybrid model were

$26612 \%, 6 \%$, and 5\% higher than those using the dynamic-flow model, respectively (Fig. 4). Annual

267 fine root (i. e. AFR + TFR) production, mortality, and decomposition were $119 \pm 9,133 \pm 7$, and

$268124 \pm 11 \mathrm{~g} \mathrm{~m}^{-2}$ (mean $\pm \mathrm{SE}$ ), respectively, when measured using the dynamic-flow model and 172

$269 \pm 11,185 \pm 12$, and $171 \pm 14 \mathrm{~g} \mathrm{~m}^{-2}$ (mean $\pm \mathrm{SE}$ ), respectively, when measured using the

270 balanced-hybrid model.

271

272 Model Test

273 The measured AFR biomass in July was $28 \%$ and $15 \%$ higher than that estimated by the

274 dynamic-flow model and the balanced-hybrid model, respectively, while the measured TFR

275 biomass in July was $29 \%$ and $11 \%$ higher than that estimated by the dynamic-flow model and the 
276 balanced-hybrid model, respectively, indicating that the balanced-hybrid model is more reliable

277 than the dynamic-flow model.

278 Discussion

279 Fine root dynamics in forests have been increasingly studied by functional groups. However, 280 most of the existing studies were two-dimensional minirhizotron analysis (McCormack et al.

281 2015; Kou et al. 2018) and did not include measurements of AFR and TFR biomass and

282 necromass dynamics due to great labor and time input (Li et al. 2020b). Failing to assess the

283 biomass and necromass dynamics impedes us to characterize soil C flux dynamics through AFR

284 and TFR growth, death and decay. In this planted loblolly pine forest, AFRs had significantly

285 lower biomass than TFRs but made comparable or even significantly greater contributions to

286 total fine root production, mortality and decomposition than TFRs did. These results

287 demonstrated that two-dimensional minirhizotron analysis cannot reflect the contributions of

288 AFRs and TFRs to total fine root production, mortality and decomposition, while three-

289 dimensional, function-based study is essential to accurately quantify fine root $\mathrm{C}$ budget and

290 understand fine root dynamics.

291 Different methods had been found to yield divergent fine root estimates, but all these

292 methodological comparisons were diameter-based rather than function-based estimates

293 (Hendricks et al. 2006; Osawa and Aizawa 2012; Li and Lange 2015). This knowledge gap has

294 hindered us to identify the strengths and weaknesses of each method and characterize the C

295 allocation pattern within the root system. Our study for the first time used two types of models, a

296 litterbag-based model and a minirhizotron-based model, to assess AFR and TFR production,

297 mortality, and decomposition. AFR estimates were significantly more responsive to 
methodological difference than TFR estimates, indicating that choice of method matters when assessing AFR and TFR contributions to fine root C fluxes.

Model test showed that the balanced-hybrid model had greater estimation accuracy than the dynamic-flow model. This can be explained by the inherent differences between them. In the balanced-hybrid model, the relative production and mortality rates at the tube-soil interface are assumed to be representative of those in bulk soil. This assumption has been proved to be very likely in previous studies (Hendrick and Pregitzer 1993; Hendricks et al. 2006; Li et al. 2020a). By contrast, in the dynamic-flow model, the estimation is based on the assumptions that fine root mortality rate remains constant in a certain interval and fine root mass loss pattern in litterbags is the same as that in bulk soil. Both are unrealistic as the mortality rate has been found to vary greatly among seasons (McCormack et al. 2014; Kou et al. 2018) and the decomposer community compositions in litterbags are different from those in natural soil (Bokhorst and Wardle 2013; Li et al. 2015; Beidler and Pritchard 2017). As a result, there would be greater errors in fine root estimates using the dynamic-flow model than using the balanced-hybrid model.

$$
\text { The significantly smaller AFR estimates of the dynamic-flow model compared to the }
$$
balanced-hybrid model can be ascribed to the underestimated AFR mass loss rate by litterbags. In existing litterbag-based models including the dynamics-flow model (Osawa and Aizawa 2012; Li and Lange 2015), mortality is positively related to the production and decomposition and fine root mass loss rate is the dominant determinant in mortality estimation. Higher fine root mass loss rate results in greater mortality estimate and therefore greater production and decomposition estimates. Since both models used the same biomass and necromass data, lower mass loss rate was the only cause for the smaller AFR estimates in the dynamic-flow model estimation. 
321 Whether litterbags significantly underestimate TFR mass loss rate is still unclear. But one thing

322 is certain: litterbag studies misrepresent fine root mass loss rate by using unrepresentative root

323 materials (Kunkle et al. 2009; Fan and Guo 2010; Sun et al. 2018) and disrupting the interactions

324 between roots, soil fauna and soil microbes (Koide et al. 2011; Li et al. 2015; Beidler and

325 Pritchard 2017; Moore et al. 2020).

326 The balanced-hybrid model can continuously track the growth and death of individual AFRs

327 and TFRs while maintaining the rhizosphere associations (McCormack et al. 2015; Beidler and

328 Pritchard 2017), which makes it effective in comparing fine root estimates between functional

329 groups. By contrast, the capacity of the dynamic-flow model in distinguishing AFR and TFR

330 estimates has been severely undermined by its inherent weaknesses. First, hyphal connections

331 with AFRs and TFRs were cut off when processing the root samples in the decomposition

332 experiment, representing a major departure from in situ conditions (Koide et al. 2011; Sun et al.

333 2018). Second, AFR and TFR litterbags were placed at different locations in forest soils, which

334 results in a cofounding of spatiotemporal variation (i. e. the effect of variances in soil

335 environmental conditions on the mass loss rate could cover the inherent difference in

336 decomposability between AFRs and TFRs). For this reason, the higher estimates for AFRs than

337 for TFRs in the balanced-hybrid estimation generally reflected the real situation, while the

338 comparable estimates between AFRs and TFRs in the dynamic-flow model estimation was most

339 likely an error of the model.

\section{Conclusion}


342 The balanced-hybrid has a greater estimation accuracy than the dynamic-flow model. AFR

343 estimates are more sensitive to the differences between the two models than TFR estimates.

344 Thus, the methodological difference must be considered to accurately characterize AFR and TFR

345 dynamics and to quantify fine root $\mathrm{C}$ fluxes in forests.

347 Acknowledgments We thank Jordan Luff, Wen Lin, and Yuan Fang for their help with

348 analyzing the minirhizotron images and processing the samples. Primary supports were provided

349 by USDA NIFA (Multi-agency A.5 Carbon Cycle Science Program) award 2014-67003-22068

350 and National Natural Science Foundation of China.

351

352 Declaration of Competing Interest

353

354 The authors declare that they have no conflict of interest.

355

356

357

References

358 Addo-Danso SD, Presscott CE, Smith AR (2016) Methods for estimating root biomass and

359 production in forest and woodland ecosystem carbon studies: A review. For Ecol Manage 359:

$360 \quad 332-351$.

361 Bartlett JE, Kotrlic JW, Higgins CC (2001) Organizational Research: Determining the

362 Appropriate Sample Size in Survey Research. ITLPJ 19: 43-50. 
363 Beidler KV, Pritchard SG (2017) Maintaining connectivity: Understanding the role of root order

364 and mycelial networks in fine root decomposition of woody plants. Plant Soil 420: 19-36.

365 Brunner I, Bakker MR, Bjork RG, Hirano Y, Lukac M, Aranda X et al. (2013) Fine-root turnover

366 rates of European forests revisited: an analysis of data from sequential coring and ingrowth

367 cores. Plant Soil 362: 357-372.

368 Ding Y, Leppälammi-Kujansuu J, Helmisaari H (2019) Fine root longevity and below-and

369 aboveground litter production in a boreal Betula pendula forest. For Ecol Manage 431: 17-25.

370 Dornbush ME, Isenhart TM, Raich JW (2002) Quantifying fine root decomposition: an

371 alternative to buried litterbags. Ecology 83: 2985-2990.

372 Fan P, Guo D (2010) Slow decomposition of lower order roots: a key mechanism of root carbon

373 and nutrient retention in the soil. Oecologia 163: 509-515.

374 Ghimire B, Riley WJ, Koven CD, Mu M, Randerson JT (2016) Representing leaf and root

375 physiological traits in CLM improves global carbon and nitrogen cycling predictions. J Adv

$376 \quad$ Model Earth Syst 8: 598-613.

377 Hendrick RL, Pregitzer KS (1993) The dynamics of fine root length, biomass, and nitrogen

378 content in two northern hardwood ecosystems. Can J For Res 23: 2507-2520.

379 Hendricks JJ, Hendrick RL, Wilson CA, Mitchell RJ, Pecot SD, Guo DL (2006) Assessing the

380 patterns and controls of fine root dynamics: an empirical test and methodological review. $\mathbf{J}$ 
Ecol 94: 40-57.

382

383

384

385

386

387

388

389

390

391

392

393

394

395

396

397

398

399

400

Hertel D, Leuschner C (2002) A comparison of four different fine root production estimates with ecosystem carbon balance data in a Fagus-Quercus mixed forest. Plant Soil 239: 237-251.

Koide RT, Fernandez CW, Peoples MS (2011) Can ectomycorrhizal colonization of Pinus resinosa roots affect their decomposition? New Phytol 191: 508- 514.

Kou L, Jiang L, Fu X, Dai X, Wang H, Li S (2018) Nitrogen deposition increases root production and turnover but slows root decomposition in Pinus elliottii plantations. New Phytol 218: 1450- 1461.

Kunkle JM, Walters MB, Kobe RK (2009) Senescence-related changes in nitrogen in fine roots: mass loss affects estimation. Tree Physiol 29: 715-723.

Li A, Fahey TJ, Pawlowska TE, Fisk MC, Burtis J (2015) Fine root decomposition, nutrient mobilization and fungal communities in a pine forest ecosystem. Soil Biol. Biochem 83:76-83.

Li X, Lange H (2015) A modified soil coring method for measuring fine root production, mortality and decomposition in forests. Soil Biol Biochem 91: 192-199.

Li X, Minick KJ, Li T, Williamson JC, Gavazzi M, McNulty S, King JS (2020a) An improved method for measuring total fine root decomposition in plantation forests combing minirhizotrons with soil coring. Tree Physiol 40: 1466-1473.

Li X, Minick KJ, Luff J, Noormets A, Miao G, Mitra B, Domec J-C, Sun G, McNulty S, King JS (2020b) Effects of microtopography on absorptive and transport fine root biomass, necromass, production, mortality and decomposition in a coastal freshwater forested wetland, 
southeastern USA. Ecosystems 23: 1294-1308.

402 Li X, Zhu J, Lange H, Han S (2013) A modified ingrowth core method for measuring fine root

403 production, mortality and decomposition in forests. Tree Physiol 33: 18-25.

404 Lin C, Yang Y, Guo J, Chen G, Xie J (2011) Fine root decomposition of evergreen broadleaved 405 and coniferous tree species in mid-subtropical China: dynamics of dry mass, nutrient and $406 \quad$ organic fractions. Plant Soil 338: 311327.

Litton CM, Raich JW, Ryan MG (2007) Carbon allocation in forest ecosystems. Glob Chang Biol 13: 2089-2109.

McCormack ML, Adams TS, Smithwick EAH, Eissenstat DM (2014) Variability in root production, phenology, and turnover rate among 12 temperate tree species. Ecology 95: 22242235.

413 McCormack LM, Dickie IA, Eissenstat DM et al. (2015) Redefining fine roots improves 414 understanding of belowground contributions to terrestrial biosphere processes. New Phytol $415 \quad 207: 505-518$.

416 Moore JAM, Sulman BN, Mayes MA, Patterson CM, Classen AT (2020) Plant roots stimulate 417 the decomposition of complex, but not simple, soil carbon. Funct Ecol 34:899-910.

418 Noormets A, Gavazzi MJ, McNulty SG, Domec J-C, Sun G, King JS, Chen J (2010) Response of 419 carbon fluxes to drought in a coastal plain loblolly pine forest. Glob Chang Biol 16: 272-287. 
420 Osawa A, Aizawa R (2012) A new approach to estimate fine root production, mortality, and

421 decomposition using litter bag experiments and soil core techniques. Plant Soil 355: 167-181.

422 Pregitzer KS, DeForest JL, Burton AJ, Allen MF, Ruess RW, Hendrick RL (2002) Fine root

$423 \quad$ architecture of nine North American trees. Ecol Monog 72:293-309.

424 Santantonio D, Grace JC (1987) Estimating fine-root production and turnover from biomass and

425 decomposition data: a compartment-flow model. Can J For Res 17(8): 900-908.

426 Sun T, Hobbie SE, Berg B, Zhang H, Wang Q, Wang Z, Hättenschwiler S (2018) Contrasting

427 dynamics and trait controls in first-order root compared with leaf litter decomposition. PNAS

$428 \quad$ 115: 10392-10397.

429 Sun JJ, Gu J, Wang Z (2012) Discrepancy in fine root turnover estimates between diameter-

430 based and branch-order-based approaches: a case study in two temperate tree species. J For

$431 \quad$ Res 23: 575-581.

432 Vogt KA (1991) Carbon budgets of temperate forest ecosystems. Tree Physiol 9: 69-86.

433 Vogt KA, Vogt DJ, Bloomfield J (1998) Analysis of some direct and indirect methods for

434 estimating root biomass and production of forests at an ecosystem level. Plant Soil 200: $71-$

43589.

436 Wear DN, Greis JG, The Southern Forest Futures Project: Summary Report; USDA Forest

437 Service Southern Research Station: Washington, DC, USA, 2012; p. 54.

438 Woodward FI, Osborne CP (2000) The representation of root processes in models addressing the 
responses of vegetation to global change. New Phytol 147: 223-232.

442 Figure 1. Absorptive (AFR) and transport (TFR) fine root biomass and necromass dynamics (g $443 \mathrm{~m}^{-2}$ for the $0-0.30 \mathrm{~m}$ soil depth; $\mathrm{n}=3$; mean $\pm \mathrm{SE}$ ).

444 Note: AFR biomass and necromass have been reported in Li et al. (2020a). We use these values 445 for the purpose of comparison.

446 Figure 2. Mass loss patterns of live and dead absorptive (AFR) and transport (TFR) fine root 447 substrates measured using litterbags in a managed loblolly pine forest $(n=3$; mean \pm SE;

448 different letters stand for significant difference in means, $P<0.05$ ). The lines are the simulated 449 values using Eq. 1.

450 Figure 3. Temporal changes in production, mortality and decomposition estimates of absorptive 451 (AFR) and transport (TFR) fine roots using balanced-hybrid model (BH) and dynamic-flow 452 model $(\mathrm{DF})$ in a planted loblolly pine forest $(n=3$; mean $\pm S E)$ * stands for significant 453 difference between AFR and TFR estimates using BH, while \# represents significant difference 454 between AFR and TFR estimates using DF $(P<0.05)$.

455 Note: AFR production, mortality and decomposition estimates using balanced-hybrid model 456 have been reported in Li et al. (2020a). We use these values for the purpose of comparison.

457 Figure 4. Annual absorptive (AFR) and transport (TFR) fine root production, mortality and 458 decomposition measured using balanced-hybrid model (BH) and dynamic-flow model (DF) in a 459 planted loblolly pine forest $(n=3$; mean \pm SE). * stands for significant difference between AFR 
460 and TFR estimates using BH, while \# represents significant difference between AFR and TFR

461 estimates using DF $(P<0.05)$.

462 Table 1 Minirhizotron-image capturing and soil core sampling dates from 2016 to 2017

\begin{tabular}{lll}
\hline Dates & Minirhizotrons & Soil core \\
\hline 25-Apr & + & + \\
10-May & + & \\
28-May & + & \\
30-Jun & + & \\
12-Jul & + & + \\
28-Jul & + & \\
12-Aug & + & \\
25-Aug & + & \\
10-Sep & + & + \\
29-Sep & + & \\
18-Oct & + & + \\
25-Nov & + & \\
5-Dec & + & + \\
25-Jan & + & \\
15-Feb & + & + \\
16-Mar & + & \\
26-Apr & + & \\
\hline
\end{tabular}

463

464

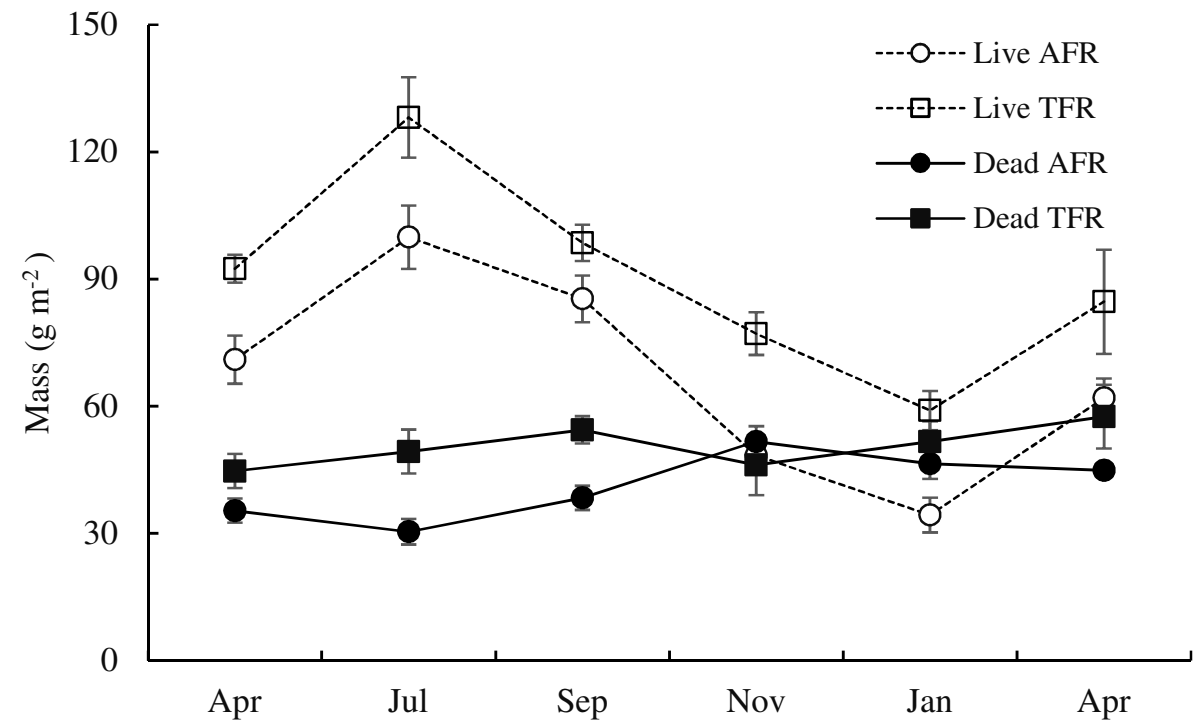

$466 \quad$ Figure 1 


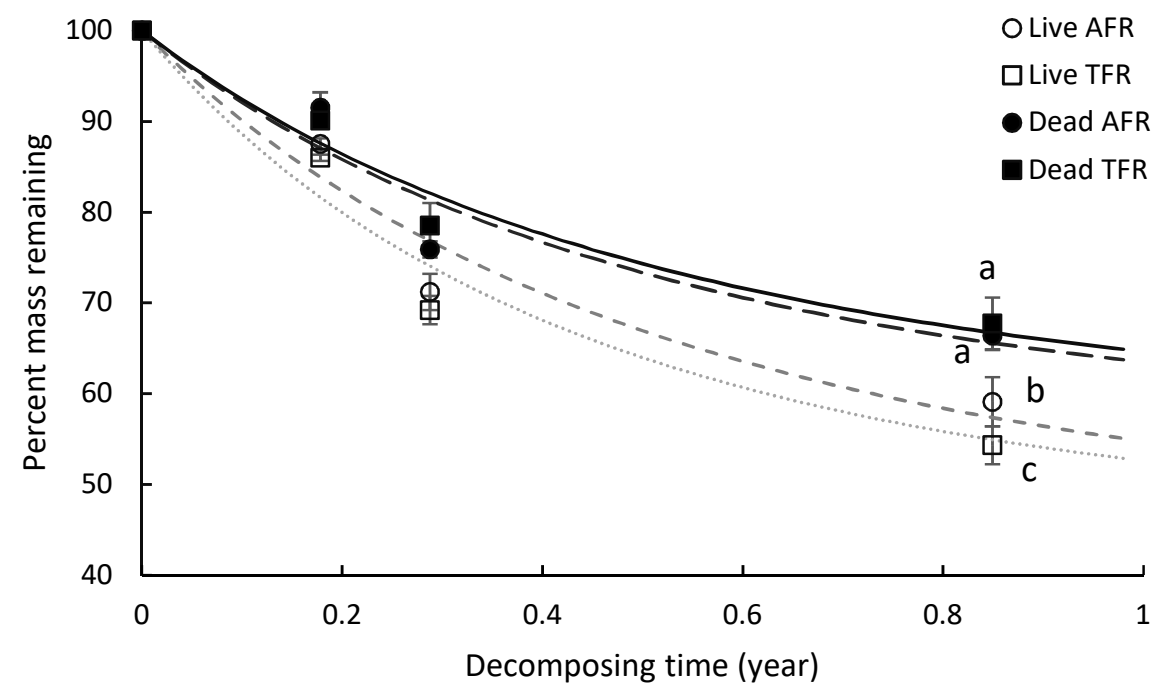

470

471 Figure 2

472 


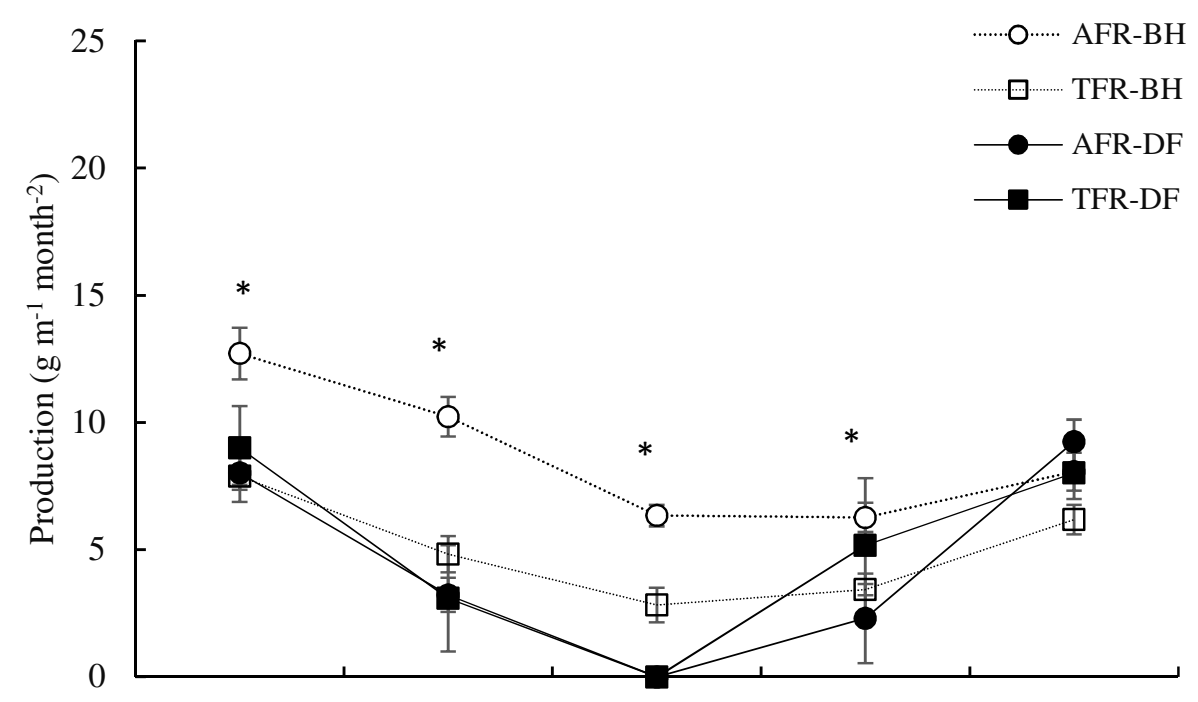

473
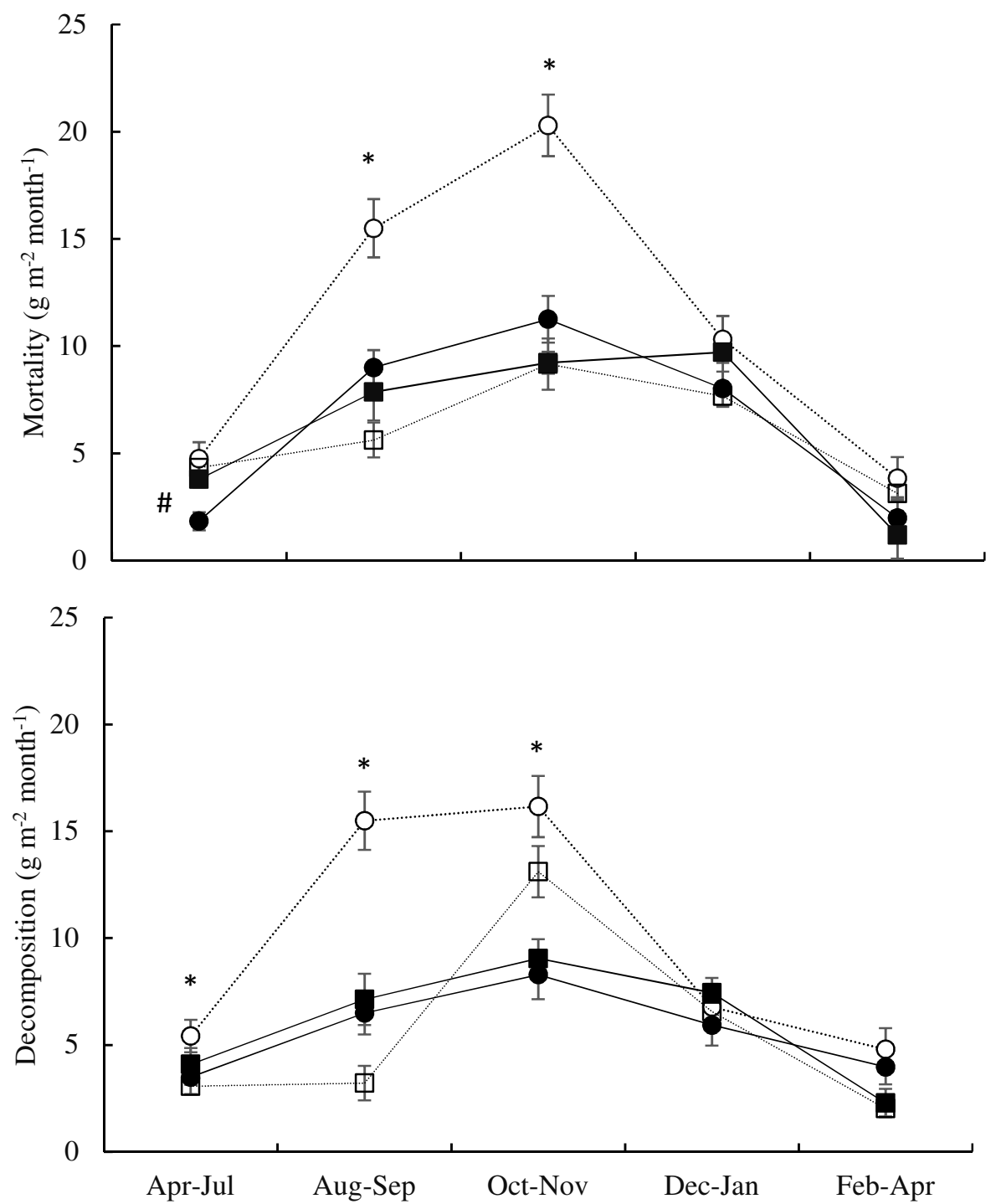

474 
$475 \quad$ Figure 3

476
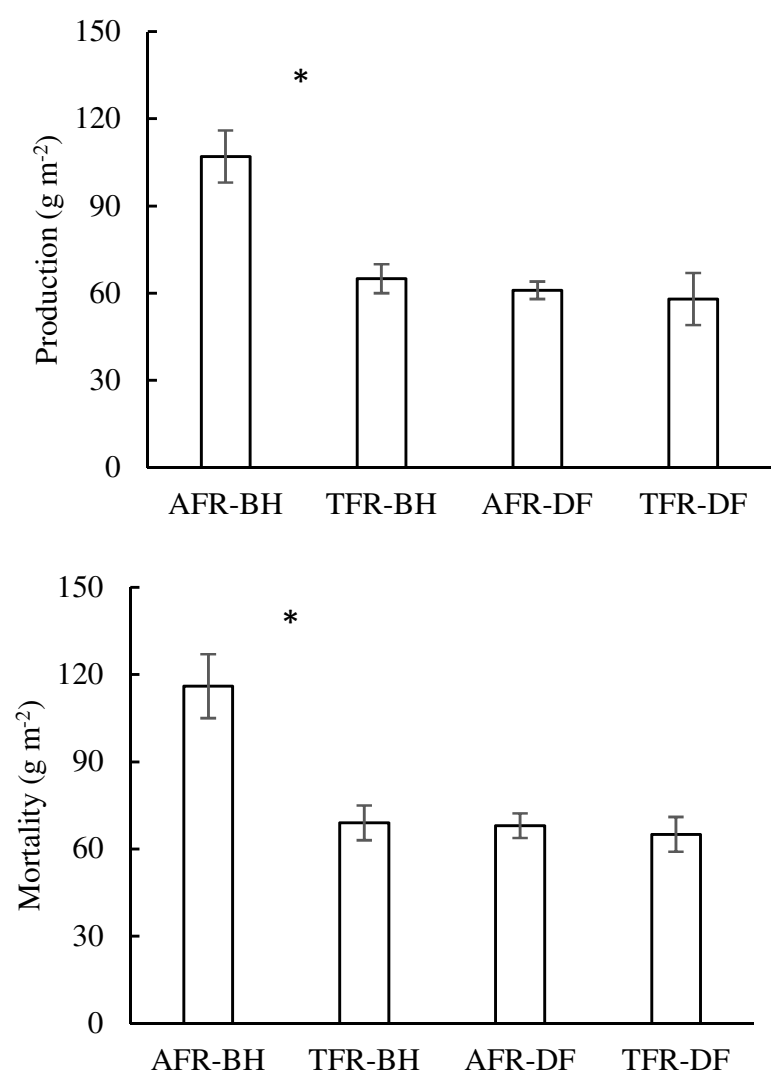

477

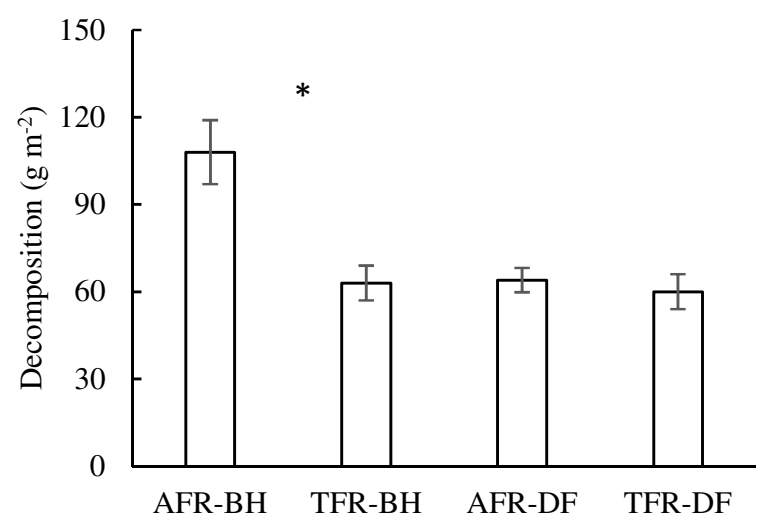

478

479

$480 \quad$ Figure 4

481

482 